\title{
SPECIAL ARTICLE Perspectives from the Society for Pediatric Research: advice on sustaining science and mentoring during COVID-19
}

Catherine S. Forster ${ }^{1}$, Suong T. Nguyen ${ }^{2}$, Weston T. Powell ${ }^{3}$, Daniel J. Moore ${ }^{4}$, Jacqueline Ho ${ }^{1}$, Melvin B. Heyman ${ }^{5}$, Tara L. Wenger ${ }^{3}$, Fernando Gonzalez ${ }^{5}$, Margaret Hostetter ${ }^{6}$, Andrew Nowalk ${ }^{1}$, Caroline E. Rassbach ${ }^{7}$, Debra Boyer ${ }^{8}$, Pnina Weiss ${ }^{9}$, Rebecca L. Blankenburg ${ }^{7}$, Jordan S. Orange ${ }^{10}$, Kate G. Ackerman ${ }^{11}$, Audrea M. Burns ${ }^{12}$ and the National Pediatric Physician-Scientist Collaborative Workgroup

The COVID-19 pandemic will leave an indelible mark on the careers of current medical trainees. Given the disruptions to medical education, economic impact on institutions, and the uncertainties around future job prospects, trainees are facing unprecedented challenges. This situation is especially concerning for futures of pediatric physician-scientist trainees, where concerns regarding maintaining the pipeline were well documented prior to the emergence of COVID-19. In this Perspectives article, we leverage the unique expertise of our workgroup to address concerns of physician-scientist trainees and to provide suggestions on how to navigate career trajectories in the post-COVID-19 era. We identified and addressed four major areas of concern: lack of in-person conferences and the associated decrease access to mentors and networking activities, decreased academic productivity, diminished job prospects, and mental health challenges. We also suggest actions for trainees, mentors and educational leaders, and institutions to help support trainees during the pandemic, with a goal of maintaining the pediatric physician-scientist pipeline.

Pediatric Research (2021) 90:738-743; https://doi.org/10.1038/s41390-020-01321-5

\section{IMPACT}

- The advice in this article will provide guidance to pediatric physician-scientist trainees on sustaining and developing their career during the continued challenges presented by COVID-19.

- We also provide suggestions for mentors, educational leaders, institutions, and professional societies on ways to help support the pediatric physician-scientist pipeline.

\section{INTRODUCTION}

The COVID-19 pandemic will leave an indelible mark on the careers of current medical trainees. In the 8 months since the appearance of coronavirus disease 2019 (COVID-19) in the United States, emerging reports have highlighted that the disruption to medical education and training due to COVID-19 will likely continue for the foreseeable future. ${ }^{1,2}$ Trainees are now facing unprecedented COVID-19-related disruptions in medical education, patient care experiences, research, financial stability of academic medical centers, and uncertainties about next stages of training and career opportunities, in addition to compounding challenges due to systemic racism. ${ }^{3}$ This situation is especially troubling for pediatric physician-scientist trainees, where concerns regarding maintaining the pipeline were well documented prior to the emergence of COVID-19. ${ }^{4-6}$ In addition to obtaining foundational clinical training, pediatric physician-scientist trainees across the continuum have additional goals of academic and research productivity in the form of presentations and publications, obtaining funding, and integrating a dual professional identity as a clinician and a scientist. ${ }^{7,8}$

As all of these areas are threatened by the COVID-19 pandemic, promoting the development and success of the pediatric physician-scientist workforce requires new strategies. The National Pediatric Physician-Scientist Collaborative Workgroup is a collaborative committee of physician-scientists, graduate medical education leaders, pediatric department chairs, and trainees with

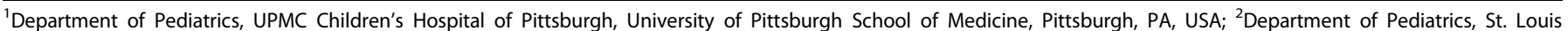

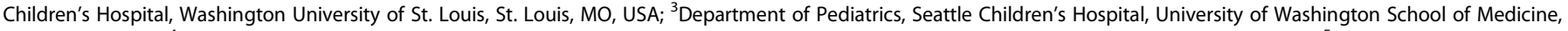

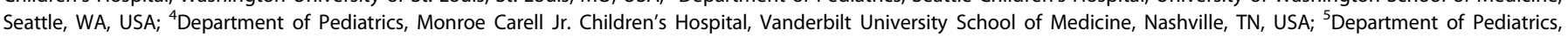

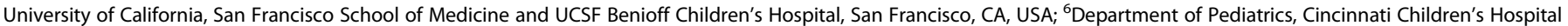

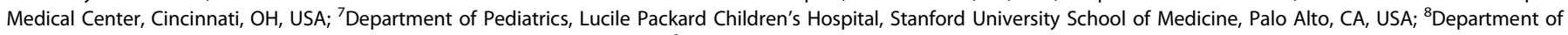

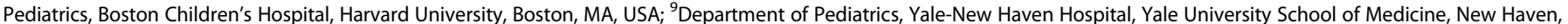

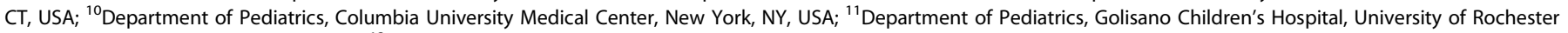
Medical Center, Rochester, NY, USA and ${ }^{12}$ Department of Pediatrics, Texas Children's Hospital, Baylor College of Medicine, Houston, TX, USA

Correspondence: Catherine S. Forster (forstercs@upmc.edu)

A full list of members and their affiliations appears in the Supplementary Information.
}

Received: 7 November 2020 Accepted: 14 November 2020

Published online: 19 January 2021 
the goal of sustaining and strengthening the pediatric physicianscientist pipeline to advance improvement in child health. The goal of this Perspectives article is to leverage the unique expertise of this workgroup to address the concerns of pediatric physicianscientist trainees, with a specific focus on residents and fellows, and to provide suggestions on how to mitigate the negative downstream impact of COVID-19 on career trajectories.

\section{IDENTIFYING CONCERNS}

We used various means to gather perspectives, including social media platforms, review of societal discussion boards and listservs, and personal communications, to gather concerns from current pediatric physician-scientist trainees and their mentors about the potential impact of COVID-19 on their career. We then identified themes from these concerns and presented them to the larger workgroup to provide advice on these topics. Three distinct concerns emerged: limited access to mentors and networking opportunities, reduced academic productivity, and fewer job prospects.

\section{DECREASED ACCESS TO MENTORS AND NETWORKING OPPORTUNITIES}

Trainees raised concerns about limited access to potential mentors and networking opportunities as the result of canceled scientific meetings and conferences. Medical and research conferences are essential for trainees to obtain feedback on research prior to publication, develop new collaborations, and reinforce the importance of pursuing physician-scientist careers. Additionally, for senior fellows poised to join the job market, national conferences facilitate networking with potential employers and provide an opportunity to build a professional identity. Much of this takes place during the informal portions of conferences, such as casual conversations and impromptu gatherings at in-person meetings, which are difficult to replicate in virtual forums. While local opportunities to engage with the research community may continue, in-person networking and collaboration on a regional, national, and international levels has been temporarily halted by the pandemic.

\section{Potential solutions}

The majority of conferences and meetings have been moved to virtual formats for the foreseeable future. One advantage of this transition is that trainees may have greater access to conferences that were previously inaccessible due to time and budget constraints, particularly international meetings. Another advantage is that virtual meetings are able to draw a greater number of attendees so trainees presenting their research may reach a larger and more diverse audience. As an example, the annual meeting of the American Physical Society, held each year in April, had approximately 4 times as many attendees in their virtual conference in 2020 than in previous year, $96 \%$ of whom logged in at some point during the conference. ${ }^{9}$ More relevant to pediatrics, the 2020 meeting of the Neonatal Heart Society was planned for having approximately 450 attendees, but in a virtual format had nearly 1500 with trainees attending at no cost. ${ }^{10}$ Increased exposure of the trainee's work can also lead to new collaborations and networking opportunities with potential opportunities for mentorship. In an effort to increase the interactivity of the online platform, virtual conferences frequently offer ways to communicate with other attendees to mimic the informal interaction of in-person meetings. These range from live chats during sessions, which offer the ability to engage with other attendees, to official mentoring activities, such as virtual speedmentoring. The committee recommends that trainees take advantage of these opportunities to the fullest extent, especially in light of the reduced costs and potential for benefit.
Alternative sources of networking include regional and institutional meetings, committees, and professional societies. Trainees should take advantage of smaller meetings, such as those on the institutional, local, and regional level, to establish and foster interpersonal connections through follow-up dialogue to cultivate shared academic interests. These are also venues in which trainees can present their scholarship and receive transdisciplinary feedback, as well as developing potential collaborations and enhancing networking. Another method to network outside of the confines of national meetings is to join local, regional, and national committees to engage with others with shared professional interests. Professional societies, both on the local and national level, recognize the challenges faced by trainees and are creating venues to highlight the work of early career researchers and provide additional networking opportunities.

Together with mentors, trainees should identify new opportunities and resources through national societies that drive support of the pediatric physician-scientist pipeline, such as the Council on Pediatric Subspecialties, American Pediatric Physician-Scientist Association, Association of Medical School Pediatric Department Chairs, Society for Pediatric Research, American Pediatric Society, Academic Pediatric Association, Association of American Medical Colleges, and subspecialty organizations, and combine those opportunities with virtual meetings and introductions to develop personal connections.

Social media has become an increasingly powerful networking platform and an important tool to network and promote work. Over the past few years, a social media presence has been viewed as an extension of professional identity with opportunities for teaching, advocacy, mentorship, research, and collaboration arising from virtual interactions. ${ }^{11,12}$ While often perceived as a networking and learning tool, social media also offers opportunity to create content in the form of blog posts, "tweetorials", podcasts, and educational tools that can be included as scholarly products in fellowship applications and CVs. ${ }^{13,14}$ It can also enable trainees to interact with potential mentors at other institutions, to gather insight into institutional character, and to learn about online seminars and other opportunities outside their home institution. As with any interaction, trainees need to be intentional with their engagement on social media platforms, perhaps more so given the record that social media creates and be aware of any institutional policies around social media use (Fig. 1).

\section{DECREASED ACADEMIC PRODUCTIVITY}

Trainees describe significant concern over their lack of academic productivity since the emergence of COVID-19. Trainees involved in basic science or translational research require bench time to complete experiments with direct mentoring, as well as time to be able to screen or recruit patients and interact with group members. Social distancing guidelines have disrupted both forms of research with implementation strategies ranging from limiting personnel in laboratories to complete shut-downs or pausing all clinical research and non-emergent clinical work. ${ }^{15}$ Personal disruptions from COVID-19 (personal or family illnesses, childcare needs including stay-at-home school age children, etc.) also factor significantly into decreased productivity. Pediatric physicianscientist trainees tend to be older when they start residencies due to prior research experience and are more likely to have children during residency and fellowship than their peers, making it more likely that elder and childcare responsibilities would affect productivity. ${ }^{16,17}$ Further, this decreased productivity during COVID-19 has disproportionately impacted female academic medicine researchers. ${ }^{18}$

Disruption in research productivity will likely result in altering and prolonging timelines for completion of projects and publications. However, prolonged training is associated with rising educational debt and opportunity cost of longer times to faculty 


Start local, explore broadly
- Follow colleagues, friends, and
programs with whom you have
existing relationships
- Follow programs and people you
want to learn about
- Browse and explore the
connections and posts of your
initial connections to add breadth
to your feed
- Curate your following list as
your interests develop
- Look for opportunities to learn
and engage (i.e., Tweetorials,
journal clubs, professional
societies, journal articles,
meetings)
- Engage to your level of comfort
and availability

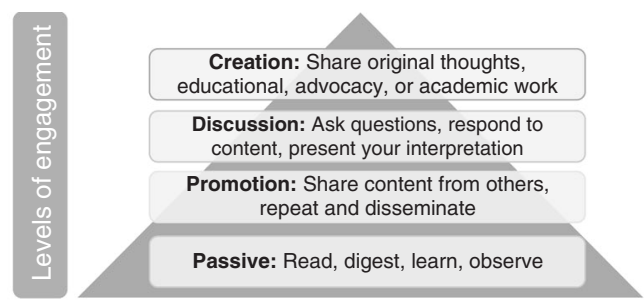

Best practice tips
- Would you repeat or endorse this in person?
- Recognize that social media keeps a record
- Proofread and fact check before you post, share, or like
- Avoid any patient-specific or identifying information
- Keep your personal and professional social media separate
Example Twitter hashtags
\#Tweetiatrician, \#DoubleDocs, \#MedTwitter, \#SoMeDocs,
\#MedStudentTwitter, \#womeninmedicine, \#DiversityDocs

Fig. 1 Social media for the training of pediatric physician-scientist. Guidance and tips for pediatric physician-scientist trainees for developing a social media presence.

appointment and promotion, and has been a hypothesized reason for the declining number of physicians pursuing research careers. $^{19}$ An extension of training may further disincentivize trainees from pursuing independent research-focused careers. The burden of additional time in training will likely fall disproportionately on trainees without sufficient resources to allow for additional time with a potentially lower salary, limiting the pediatric physician-scientist pipeline and further restricting its diversity.

\section{Potential solutions}

An important early career goal is to gain skills that will advance both current and future research. Delays in research due to COVID19 provide an opportunity to complete training or coursework to gain additional skills necessary for career development while current hands-on research may be delayed. Trainees should think critically about the skills they need to either complete a project or to progress into the next phase of research, while exploring relevant training opportunities that will be beneficial in their future work. For trainees early in their career who find it difficult to identify specific skills, online coursework on basic study design, grant writing, or introductions to commonly used statistical software would be beneficial or could provide a foundation for their career in academic medicine. Developing a modified timeline for the upcoming academic year that can be revisited quarterly through dialogue with mentorship can help to hone and refine foundational skills critical for early career success. Furthermore, many free, high-quality massive open online courses are available that cover a wide range of topics, including statistics for medical research, pragmatic clinical trials, comparative research design, data analytics, big data analysis, and data visualization. The availability of such online educational opportunities enables trainees with both scheduling and financial restrictions to access resources to continue advancing their skills and knowledge.

Alternatively, trainees can focus on components of their project less impacted by COVID-19 or can seek opportunities to participate in other research projects. Starting or joining new or ongoing projects can also help diversify a trainee's skill set and add a long-term benefit to their productivity in their intended research area. Another option is to apply this time to focus on other elements of the research process, such as analyzing data and drafting research manuscripts from existing data sets and prior lower priority projects, writing protocols for either the institutional review board or institutional animal care and use committee that need to be completed before research can begin, completing required regulatory institutional training, and writing reviews that could serve as background material for grant applications.

While trainees consider navigating and enhancing their study design, research approvals, and coursework, they may also have the opportunity to integrate these new plans into writing a grant proposal that could fund their work and provide future supported research time. While not every application will be funded, trainees will gain valuable experience in grant writing, which is a critical skill for career development as a physician-scientist. When successful, career development and early career awards can help fund the transition time from fellow to independent positions. Regardless of the outcome of the grant, the process of review by senior scientists within a trainee's field can provide valuable feedback and indirectly contribute to providing critical inflection points on research aims and further nurture the individual's professional identity.

There are several funding opportunities that trainees can consider. The F32 individual award can be combined with institutional T32 grants for a total of 3 years of support to obtain an additional year of funded time to help recover the dip in productivity while showcasing prowess in obtaining federal funding and learning the skills needed to assemble a complete, competitive application. The NIH's Loan Repayment Program (LRP; www.Irp.nih.gov) is another opportunity to practice grant-writing skills, while also, if awarded, offsetting the financial burden associated with prolonged training. The LRP stipulates that applicants have a certain degree of institutionally supported research time and therefore is more applicable to fellows and junior faculty that have significant allocated time for research. Finally, foundations and research societies also offer training grant/early career support, and despite the economic downturn, many foundations are trying to preserve grants for early career researchers.

It is important to reassure trainees that they are not alone in facing the challenges of decreased productivity during COVID-19. All levels of academic medicine are impacted. Trainees and mentors should be open in discussing those challenges as some colleagues and acquaintances may seem unimpacted or even experience a productivity boost during this time. Seeing this play out among peers or on social media can be very discouraging. Trainees should be reminded that they are not defined solely by their most recent productivity; their vision and passion and when 
communicated effectively are equally important, especially during their early career.

\section{DIMINISHED JOB PROSPECTS}

The lack of clarity around the future job market is a major area of concern for trainees, especially for those seeking academic positions. While the Accreditation Council for Graduate Medical Education advocated that residents and fellows be protected from furloughs, the unprecedented financial challenges on academic medical systems during the COVID-19 pandemic has forced economic restructuring that includes implementation of hiring freezes, pay and benefit reductions, and elimination of new fellow and faculty positions..$^{20,21}$ Senior fellows aiming to transition to the next phase of their career face a changing and uncertain job market and funding environment. Challenges in both recruiting and retaining trainees into the pediatrician-scientist pipeline were already present prior to the onset of the COVID-19 pandemic. Scarce institutional seed funds for physician-scientist faculty may become more scarce still. Potential implications of COVID-19 on the academic job market may irrevocably harm this already tenuous course.

\section{Potential solutions}

Job searching during the COVID-19 pandemic presents a unique challenge. It is difficult to predict what the evolving hiring landscape will be or how it will change with the current political and economic uncertainty. Some universities are likely able to continue to hire talented pediatric physician-scientists. However, it will be important for those entering the job market to adjust expectations. Retaining pre-COVID-19 expectations will make it difficult to identify and accept the opportunities that exist in the current environment, thus missing out on ones that might have potential to blossom following immediate post-COVID-19 recoveries. By late fellowship, many pediatric physician-scientists will have had significant mentoring regarding a "good" job offer, particularly in terms of resources and institutionally supported time. While positions may not offer the previously anticipated opportunities, jobs are likely to still be available in institutions where a candidate could thrive. Candidates will need to work with their mentors and advisors to recalibrate what the candidate requires to support success in the next stage of career development. An appropriate question might be instead of what the institutional support might be, what is the anticipated timeline to further institutional support for research. It will be important not to miss good opportunities just because the current jobs differ now compared with those offered prior to COVID-19.

In navigating this new job market, it is important to remember that opportune jobs will still be available. In all cases, candidates must know the potential employers' expectations and resources, identify available support systems, current institutional support for current pediatric physician-scientists, and identify the institution's medium-term vision for managing this continuing crisis. While these questions were important pre-pandemic, they are now critical to assessing different opportunities. Our advice to trainees is to choose institutions that have committed to continue to provide as many resources to trainees as possible, as these institutions will likely continue to provide support and resources to early pediatric physician-scientists. An additional option, for those trainees who have the personal resources to do so, would be to add an additional year to fellowship or consider an instructorship and join the assistant professor job market in a time hopefully less affected by COVID- 19 .

Another aspect of looking for fellowships or jobs during this pandemic is the change in the interview process. While virtual interviews have generated anxiety and uncertainty with the application process, in many ways, this increased accessibility will make it easier to explore more programs than were possible during the pre-COVID-19 era. As the community has become more comfortable with virtual interactions, video meetings can be scheduled with prospective programs to discuss their research opportunities. Mentors can be a resource in identifying prospective programs, and programs may support trainees by providing them with both time and physical space from which to make these connections.

\section{MENTAL HEALTH AND WELLNESS}

A final consideration, although not one directly listed by the respondents, is the effect of COVID-19 on trainees' mental health and wellness. Living through a pandemic has had an enormous toll on mental health, independent of the concerns that we have discussed. Furthermore, front-line clinicians, such as residents and fellows, have also reported high levels of stress across multiple domains during the COVID-19 pandemic. ${ }^{22}$ The combination of these larger concerns, in addition to the anxiety over productivity and future job prospects, places an enormous strain on pediatric physician-scientist trainees. Therefore, in providing advice to this generation of pediatric physician-scientist trainees, we felt it necessary to acknowledge the mental health burden of this pandemic and to provide suggestions to strengthen resilience.

\section{Potential solutions}

In an article written in March 2020, Dr. Aisha Ahmad suggested a three-stage approach to working during a crisis: (1) security, (2) making a mental shift, and (3) embracing the new normal. In this piece, she writes, "Know that you are not failing. Let go of all of the profoundly daft ideas you have about what you should be doing right now. Instead, focus intensely on your physical and psychological security". ${ }^{23}$ This statement strikes at the heart of the matter, which is expectations regarding productivity, and emphasizes the need to focus on each individual's psychological state. We must all acknowledge that the stress of loneliness and a disconnected electronic life where the majority of interactions occur via electronic platforms can lead to moral distress, which can result in personal injury. ${ }^{19}$ These mental health stressors, challenges, and responses are present yet unique for everyone. For example, some may experience loneliness while others may experience not enough alone time. For those trainees with child and elder care responsibilities, there are added anxieties around navigating elder care, childcare, day care, and hybrid schedules of virtual and in-person school. Equally important are the pervasive challenges for many in dealing with the overwhelming and repeated crises surrounding racial injustice, gender inequities, and health disparities. We encourage trainees to take this opportunity to embrace the chance to explore and actually use mental health resources offered by their institutions. We hope that program leaders will convene psychologically safe forums where people can share their frustrations and fears as well as best practices for navigating these very stormy waters. It is important that programs continue to meet people where they are and to provide an array of resources including mental health access, wellness initiatives, one-on-one check-ins, and reassurance from leadership around the plan to care for career development and advancement of all individuals.

\section{PERSPECTIVES FROM SPR, A CALL TO ACTION}

Pediatric physician-scientist trainees are crucial to the future of pediatric research and child health. The COVID-19 pandemic presents even more challenges to an already threatened pipeline. The challenge must be met by all of those engaged in academic pediatrics to provide support for our trainees as they navigate these unprecedented times (Table 1). 
Table 1. Suggested actions for trainees, mentors and educational leaders, and institutions and societies.

\begin{tabular}{|c|c|c|c|}
\hline Domain & Trainees & Mentors and educational leaders & Institutions and societies \\
\hline \multirow[t]{4}{*}{ Networking } & Attend virtual meetings & Help identify networking opportunities & Host virtual networking events for trainees \\
\hline & $\begin{array}{l}\text { Join local and national } \\
\text { committees }\end{array}$ & & \\
\hline & $\begin{array}{l}\text { Engage in virtual networking } \\
\text { session }\end{array}$ & Participate in local networking events & $\begin{array}{l}\text { Provide forums for trainees to present } \\
\text { their research virtually }\end{array}$ \\
\hline & $\begin{array}{l}\text { Develop a social media } \\
\text { presence }\end{array}$ & Provide connections for trainees & $\begin{array}{l}\text { Provide incentives to mentors to } \\
\text { participate in virtual networking events }\end{array}$ \\
\hline \multirow[t]{3}{*}{$\begin{array}{l}\text { Decreased } \\
\text { productivity }\end{array}$} & Focus on developing key skills & $\begin{array}{l}\text { Help trainees to revise individual development plans } \\
\text { and identify virtual training opportunities }\end{array}$ & $\begin{array}{l}\text { Provide virtual training opportunities } \\
\text { specifically for trainees }\end{array}$ \\
\hline & Consider writing a grant & Help identify funding opportunities & Provide small pilot grants for trainees \\
\hline & $\begin{array}{l}\text { Pivot to participate in research } \\
\text { that has continued }\end{array}$ & & \\
\hline \multirow[t]{3}{*}{ Jobs } & Explore a variety of institutions & Help adjust expectations to current climate & \multirow{3}{*}{$\begin{array}{l}\text { Provide support for extra year of training } \\
\text { for fellows }\end{array}$} \\
\hline & $\begin{array}{l}\text { Work with mentors to identify } \\
\text { opportunities }\end{array}$ & Provide connections for trainees & \\
\hline & Consider extra year of training & & \\
\hline \multirow[t]{2}{*}{ Mental health } & Be kind to yourself & Provide optional open forums for trainees to vent & \multirow{2}{*}{$\begin{array}{l}\text { Remove barriers to accessing institutional } \\
\text { mental health services }\end{array}$} \\
\hline & $\begin{array}{l}\text { Take advantage of institutional } \\
\text { mental health resources }\end{array}$ & Be available and present for trainees & \\
\hline
\end{tabular}

Implications for residents and fellows

Medical training is a long, strenuous process that was challenging before the appearance of COVID-19. Pediatric physician-scientist trainees have the additional task of obtaining research skills and demonstrating academic productivity, while ensuring they develop the necessary clinical skills needed to care for patients. The changes wrought by the COVID-19 pandemic have created additional stressful challenges for trainees. Now, more than ever, trainees will need to rely on their peers, mentors, and program leadership for support and advice on how to navigate these challenges and engage in newly emerging support networks through pediatric societies. Leaders and mentors in pediatrics must be ready to accept and adapt to these challenges to limit the threats and burdens facing trainees in response to the enthusiasm and creativity trainees will bring.

Implications for mentors, educational leaders, institutions, and professional societies

Trainees will need extra support during this pandemic. Mentors, researchers, educational leaders, and institutions all play a role in supporting trainees. Mentors need to assist with networking, as traditional avenues are not currently available. Mentors can also encourage trainees to create, or revise if one already exists, an independent development plan to help trainees identify and attain key skills. Established researchers should seek out opportunities to aid trainees in providing supplemental training to advance existing research projects, enable alternative research projects, or assist with creating connections with other researchers in the field. Residency and fellowship program directors need to provide support and compassion for those navigating these stressful situations and share expanding resources for supporting wellbeing. Professional societies need to provide opportunities to highlight trainees, provide funding, and promote early-career scientists. If institutions or societies are offering virtual mentoring opportunities, consider providing a small incentive for mentors who are also experiencing a high degree of "zoom fatigue" and may be less likely to volunteer for these opportunities. Finally, institutions need to be mindful of the burden and stress placed on all those involved in training, from the trainees themselves to their mentors and educational leaders. If feasible, emphasis should be placed on high-value supports, such as supplemental funds to support fellows for an additional year or provide small pilot grants to offset research costs for trainee projects. Finally, institutions and societies, who may have a larger influence than individual researchers, should engage in advocacy to funding agencies to provide unconventional support to sustain the pediatrician pipeline.

We all must work together to focus on supporting our trainees through this time and reaffirm their value. Without this effort, the pediatric physician-scientist pipeline will continue to dwindle, threatening the future of pediatric research and improvement of child health. At the same time, the creation of support systems that are robust enough to face a global pandemic are likely to be the strongest foundation we have had to date to sustain and enrich the pediatric physician-scientist pipeline. The opportunity for a brighter future has never been greater or more urgent.

\section{AUTHOR CONTRIBUTIONS}

All authors made substantial contributions to the conception and design of the article, made critical revisions for important intellectual content, and approved the version to be published. In addition to the above, C.S.F., S.T.N., and W.T.P. co-wrote the first draft of the manuscript.

\section{ADDITIONAL INFORMATION}

The online version of this article (https://doi.org/10.1038/s41390-020-01321-5) contains supplementary material, which is available to authorized users.

Competing interests: The authors declare no competing interests.

Publisher's note Springer Nature remains neutral with regard to jurisdictional claims in published maps and institutional affiliations.

\section{REFERENCES}

1. Shah, J. P. The impact of COVID-19 on head and neck surgery, education, and training. Head Neck. 42, 1344-1347 (2020).

2. Escalon, M. X., Raum, G., Tieppo Francio, V., Eubanks, J. E. \& Verduzco-Gutierrez, M. The immediate impact of the coronavirus pandemic and resulting adaptations in physical medicine and rehabilitation medical education and practice. $P M R \mathbf{1 2}$, 1015-1023 (2020).

3. Cutler, D. How will COVID-19 affect the health care economy? JAMA 323, 2237-2238 (2020) 
4. Cornfield, D. N., Lane, R. \& Abman, S. H. Creation and retention of the next generation of physician-scientists for child health research. JAMA 309, 1781-1782 (2013).

5. Burns, A. M. et al. Fixing the leaky pipeline: identifying solutions for improving pediatrician-scientist training during pediatric residency. Pediatr. Res. 88, 163-167 (2020).

6. Shurin, S. B. The American Pediatric Society commentary: The future of pediatric physician scientists is in our hands. Arch. Pediatr. Adolesc. Med. 166, 503-505 (2012).

7. Rosenblum, N. D., Kluijtmans, M. \& Ten Cate, O. Professional identity formation and the clinician-scientist: a paradigm for a clinical career combining two distinct disciplines. Acad. Med. 91, 1612-1617 (2016).

8. Burns, A. M. et al. Strengthening the pipeline for clinician-scientists: the pediatrician-scientist training and development program at Texas Children's Hospital. J. Pediatr. 172, 5-6.e5 (2016)

9. Viglione, G. How scientific conferences will survive the coronavirus shock. Nature 582, 166-167 (2020).

10. NeoHeart 2020: cardiovascular management of the neonate. https://web.cvent. com/event/2fb59f4f-ac0e-4074-b856-99656d06ab65/summary (2020).

11. O'Glasser, A. Y., Jaffe, R. C. \& Brooks, M. To tweet or not to tweet, that is the question. Semin. Nephrol. 40, 249-263 (2020).

12. Mikolajczyk, A. E. et al. \#LiverTwitter: an emerging tool for liver education and research. Hepatol. Commun. 4, 1229-1233 (2020).

13. Breu, A. C. From tweetstorm to tweetorials: threaded tweets as a tool for medical education and knowledge dissemination. Semin. Nephrol. 40, 273-278 (2020).
14. Breu, A. C. Why is a cow? Curiosity, tweetorials, and the return to why. N. Engl. J. Med. 381, 1097-1098 (2019).

15. Tuttle, K. R. Impact of the COVID-19 pandemic on clinical research. Nat. Rev. Nephrol. 16, 562-564 (2020).

16. Andriole, D. A., Whelan, A. J. \& Jeffe, D. B. Characteristics and career intentions of the emerging MD/PhD workforce. JAMA 300, 1165-1173 (2008).

17. Cardel, M. I., Dean, N. \& Montoya-Williams, D. Preventing a secondary epidemic of lost early career scientists: effects of COVID-19 pandemic on women with children. Ann. Am. Thorac. Soc. 17, 1366-1370 (2020).

18. Gabster, B. P., van Daalen, K., Dhatt, R. \& Barry, M. Challenges for the female academic during the COVID-19 pandemic. Lancet 395, 1968-1970 (2020).

19. Borges, N. J., Navarro, A. M., Grover, A. \& Hoban, J. D. How, when, and why do physicians choose careers in academic medicine? A literature review. Acad. Med. 85, 680-686 (2010).

20. Termini, C. M. \& Traver, D. Impact of COVID-19 on early career scientists: an optimistic guide for the future. BMC Biol. 18, 95 (2020).

21. Robbins, S. L. et al. The impact of the COVID-19 shutdown on US pediatric ophthalmologists. J. AAPOS 24, 189-194 (2020).

22. Lai, J. et al. Factors associated with mental health outcomes among health care workers exposed to coronavirus disease 2019. JAMA Netw. Open 3, e203976 (2020).

23. Ahmad, A. Why you should ignore all that coronavirus-inspired productivity pressure. https://www.chronicle.com/article/why-you-should-ignore-all-that-coronavirusinspired-productivity-pressure/ (2020). 